\title{
KUALITAS LEMAK TENGKAWANG HASIL PRODUKSI PROTOTIPE ALAT PRES TENGKAWANG BERTENAGA HIDROLIK
}

\section{QUALITY OF BORNEO TALLOW NUT FAT EXTRACTED FROM HYDRAULIC-POWERED PRESS PROTOTYPE MACHINE}

\author{
Oleh: \\ Andrian Fernandes dan Rizki Maharani \\ Balai Besar Penelitian dan Pengembangan Ekosistem Hutan Dipterokarpa, Samarinda \\ Jalan A.W. Syahranie No.68, Sempaja, Samarinda Telp. (0541) 206364 Fax, (0541) 42298 \\ af.andrian.fernandes@gmail.com
}

Diterima 23-10-2017, direvisi 22-12-2017, disetujui 29-12-2017

\begin{abstract}
ABSTRAK
Pengolahan Tengkawang menjadi lemak diperoleh melalui proses ekstrasi biji tengkawang, yang mengandalkan pada proses pres biji tersebut. Tradisi pengolahannya masih tradisional sehingga rendemen maupun kualitas hasil olahan minyaknya belum optimal. Dalam studi ini diperkenalkan prototipe alat pres biji Tengkawang bertenaga hidrolik dengan bahan anti karat standar khusus kualitas bahan pangan (stainless stell for food grade) yang berkapasitas tekan hingga 1 ton. Selanjutnya kualitas lemak diuji menggunakan standar SNI 3748-2009 pendekatan uji kualitas lemak Kakao. Hasil uji lemak Tengkawang produksi prototipe ini menunjukkan bahwa terjadi peningkatan rendemen optimum mencapai 42,68\%. Kualitas lemak yang dihasilkan menunjukkan nilai berat jenis lemak $0,90 \mathrm{~g} / \mathrm{cm}^{3}$, indeks bias 1,45 , titik leleh $31^{\circ} \mathrm{C}$, bilangan iodium $16,46 \mathrm{mg} / \mathrm{kg}$, bilangan penyabunan $449,21 \mathrm{mg} / \mathrm{g}$ dan asam lemak bebas $10,07 \%$. Karakteristik lemak Tengkawang hasil produksi prototipe alat mesin pres hidrolik ini sebanding bahkan lebih baik dari standard kualitas lemak Kakao uji dan dapat langsung diaplikasikan untuk diversifikasi produk lemak Tengkawang lainnya.
\end{abstract}

Kata Kunci: Lemak Tengkawang, prototipe, alat pres hidrolik, rendemen, kualitas lemak

\begin{abstract}
Borneo tallow is extracted from tengkawang seeds, which the result highly depends on seed press processing. Yet, traditional processing is still being used so that the yield and quality of extracted oil has not been optimal. In this study, prototype of Tengkawang hydraulic-powered press prototype machine equipped with stainless food grade material was used in oil extraction. The machine has press capacity up to 1 ton. Furthermore, fat quality was tested using SNI 3748-2009 standard adopting a similar approach as cocoa fat quality test. Result showed that there was an increase of optimum yield by $42.68 \%$ by using this machine. Meanwhile, the result of fat quality test showed fat density of 0.90 $\mathrm{g} / \mathrm{cm}^{3}$, refractive index 1.45 , melting point $31^{\circ} \mathrm{C}$, iodine value $16.46 \mathrm{mg} / \mathrm{kg}$, saponification value $449.21 \mathrm{mg} / \mathrm{g}$ and fatty acid free (FFA) 10.07\%. The fat characteristics of Tengkawang oil generated from prototype machine are comparable, even better than cocoa fat quality test standard and can be directly applied to diversify other Tengkawang fat products.
\end{abstract}

Keywords: Borneo tallow-nut, prototype, hydraulic press tool, yield, fat quality

\section{PENDAHULUAN}

Salah satu jenis lemak nabati yang banyak digunakan adalah lemak Tengkawang (Jahurul et al, 2013). Lemak Tengkawang memiliki komposisi yang hampir sama dengan lemak cokelat dan dapat digunakan secara langsung untuk menggantikan lemak cokelat tanpa proses pengolahan lebih lanjut (Gunstone, 2011). 
Pengolahan Tengkawang menjadi lemak Tengkawang diperoleh dari proses ekstraksi biji Tengkawang. Tradisi pengolahan lemak Tengkawang dapat dijumpai di Kalimantan Barat (Maharani et al, 2016). Proses pengolahan lemak Tengkawang secara tradisional menggunakan alat yang dikenal dengan nama “Apit" dengan kapasitas sekitar 4-5 kg sekali proses. Proses pengolahan lemak Tengkawang secara tradisional meliputi penumbukan biji Tengkawang kering, pengukusan serbuk biji Tengkawang dan pengepresan serbuk Tengkawang. Keseluruhan proses tersebut memerlukan tenaga dan sumber daya yang besar.

Berdasarkan informasi dari masyarakat lokal, di Bengkayang, Kalimantan Barat pada tahun 2015 menghasilkan 700 kg biji Tengkawang kering. Sumarhani (2007) menyatakan bahwa pada saat panen raya, pohon Tengkawang yang produktif pada usia 30 hingga 100 tahun dapat menghasilkan buah sebanyak 250-400 kg per pohon. Dengan jumlah panen biji Tengkawang yang besar, maka proses pengolahan secara tradisional menggunakan "Apit" menjadi tidak efektif. Oleh karena itu perlu dibuat prototipe alat pres Tengkawang dengan kapasitas produksi yang lebih memadai dan dapat diaplikasikan dengan mudah dan praktis.

\section{METODOLOGI PENELITIAN}

Prototipe alat pres Tengkawang dibuat menjadi dua bagian, yaitu unit boiler dan unit pengepres. Unit boiler berfungsi sebagai sumber uap panas yang 50 dipakai untuk memanaskan biji Tengkawang. Unit pengepres menggunakan sistem hidrolik bertenaga mesin bensin. Unit pengepres yang berfungsi untuk mengepres biji Tengkawang dibuat dengan bahan anti karat berkualitas khusus untuk bahan pangan (stainless stell food grade). Dewangan et al (2015) penggunaan bahan anti karat bertujuan untuk menjaga kemurnian hasil produk olahan bahan pangan.

Percobaan pengepresan dilakukan sebanyak 2 (dua) ulangan, masing-masing ulangan menggunakan bahan baku 3,5 kg biji Tengkawang kering jenis Shorea mecistopteryx yang diperoleh dari Bengkayang, Kalimantan Barat. Biji Tengkawang kering dimasukkan ke dalam unit mesin pres dan dialirkan uap yang berasal dari unit boiler ke unit mesin pres. Tekanan uap sebesar 3 bar. Biji Tengkawang dipanaskan dengan suhu $110^{\circ} \mathrm{C}$ selama 1 jam. Selanjutnya dipres dengan mesin selama 30 menit.

Lemak Tengkawang yang dihasilkan prototipe alat pres diuji kualitasnya dan mengacu pada SNI 37482009 tentang lemak Kakao. Pengujian kualitas lemak Tengkawang meliputi berat jenis, indeks bias, titik leleh, bilangan iodium, bilangan penyabunan dan asam lemak bebas.

\section{HASIL DAN PEMBAHASAN}

Hasil pembuatan prototipe alat pres dapat dilihat pada gambar berikut ini. 


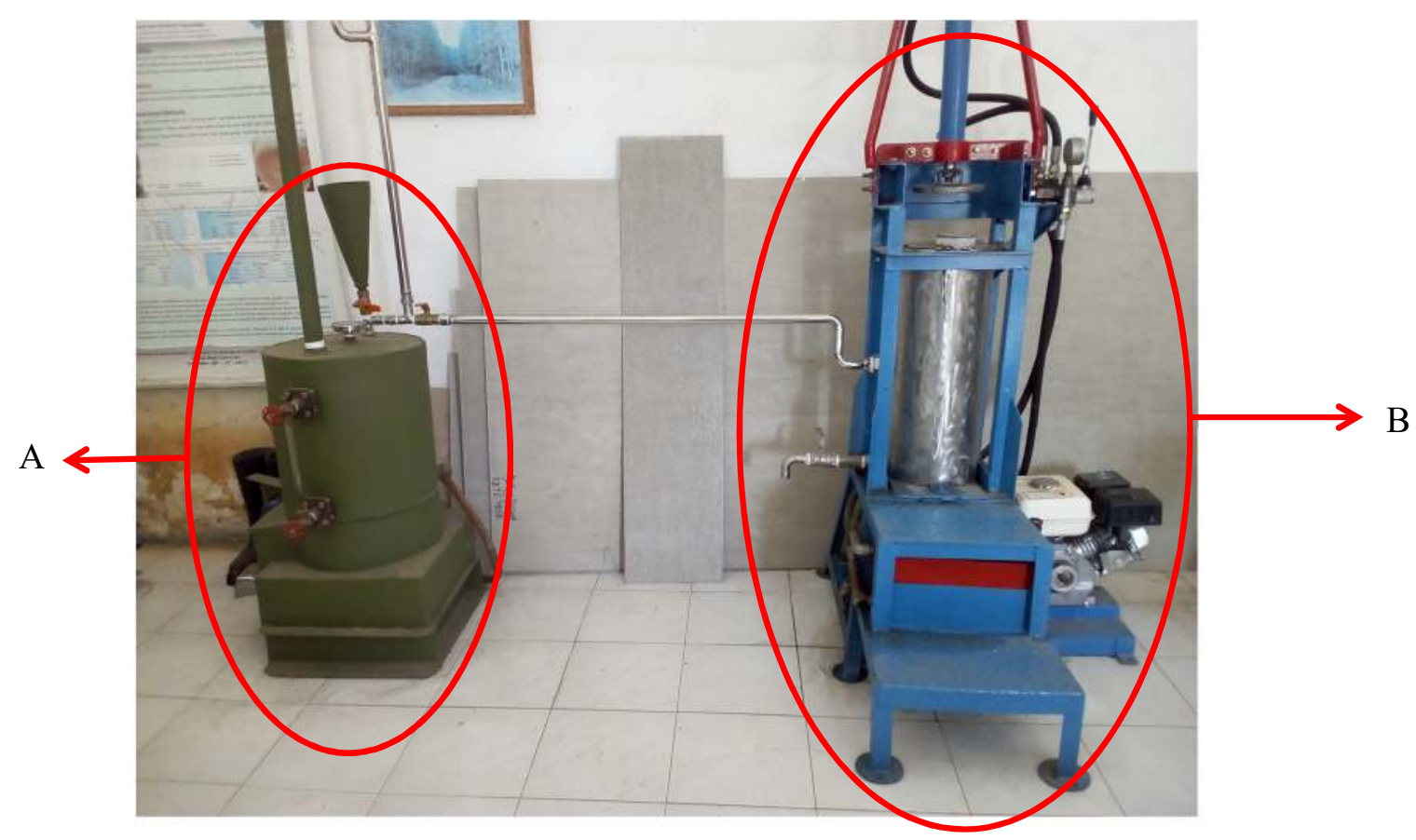

Gambar 1. Prototipe alat pres Tengkawang bertenaga hidrolik ( $\mathrm{A}=$ unit boiler dan $\mathrm{B}=$ unit pengepres); Sumber foto : dokumentasi pribadi.

Picture 1. Prototype of hydraulic powered Tengkawang press machine ( $A=$ boiler unit and $B=$ pressing unit); Source: author collection.

Pada proses "Apit", serbuk biji Tengkawang kering dikukus dalam drum menggunakan bahan bakar kayu. Sedangkan pada prototipe alat pres Tengkawang menggunakan steam boiler unit. Steam boiler unit merupakan salah satu cara pemanasan yang banyak digunakan dalam proses industri (Ohijeagbon et al, 2013). Boiler dapat menggunakan bahan bakar berupa kayu, serbuk kayu, kulit buah Tengkawang, ampas Tengkawang yang sudah dipres maupun kompor minyak. Boiler berfungsi untuk melelehkan minyak sehingga mudah keluar dari dalam biji Tengkawang.

Pengolahan biji Tengkawang menjadi lemak Tengkawang secara tradisional menggunakan "Apit", yang bekerja dengan menggunakan "pasak" yang dipukul dan sistem ini tergolong dalam kondisi beban kerja berat. Salah satu cara modern untuk menangani kondisi beban pekerjaan yang berat adalah menggunakan sistem hidrolik (Quan et al, 2014). Prototipe alat pres Tengkawang bekerja dengan sistem hidrolik dengan kapasitas tekan hingga 1-ton yang berfungsi untuk menekan biji Tengkawang kering yang keras.

Bagian "Apit” yang berfungsi sebagai pres serbuk biji Tengkawang berupa kayu, sedangkan pada prototipe alat pres berbahan baku stainless stell food grade. Penggunaan bahan baku stainless stell food grade akan mempermudah proses pemeliharaan dan pembersihan prototipe alat pres. 
Tabel 1. Kualitas lemak Tengkawang hasil prototipe mesin pres.

Table 1. Quality of Tengkawang Fat from Prototype Press Machine.

\begin{tabular}{|l|r|r|r|r|}
\hline \multicolumn{1}{|c|}{$\begin{array}{c}\text { Parameter } \\
\text { Parameters }\end{array}$} & $\begin{array}{c}\text { Ulangan 1 } \\
\text { (First Repitition) }\end{array}$ & $\begin{array}{c}\text { Ulangan 2 } \\
\text { (Second Repitition) }\end{array}$ & $\begin{array}{l}\text { Rata-rata } \\
\text { (Average) }\end{array}$ & $\begin{array}{c}\text { Lemak Tengkawang dari } \\
\text { Sahan } \\
\text { Tengkawang fat from Sahan } \\
\text { (Maharani et al, 2016) }\end{array}$ \\
\hline $\begin{array}{l}\text { Rendemen lemak (\%) } \\
\text { Fat yielded (\%) }\end{array}$ & 43,78 & 41,94 & 42,86 & 0,90 \\
\hline $\begin{array}{l}\text { Berat jenis }\left(\mathrm{g} / \mathrm{cm}^{3}\right) \\
\text { Density }\left(\mathrm{g} / \mathrm{cm}^{3}\right)\end{array}$ & 0,90 & 0,90 & 0,90 & 29,45 \\
\hline $\begin{array}{l}\text { Indeks bias } \\
\text { Refractive index }\end{array}$ & 1,45 & 1,45 & 1,45 & 20,00 \\
\hline $\begin{array}{l}\text { Titik leleh }\left({ }^{0} \mathrm{C}\right) \\
\left.\text { Melting point }{ }^{\circ} \mathrm{C}\right)\end{array}$ & 31,00 & 31,00 & 31,00 & 423,35 \\
\hline $\begin{array}{l}\text { Bilangan iodium }(\mathrm{mg} / \mathrm{kg}) \\
\text { Iodine number }(\mathrm{mg} / \mathrm{kg})\end{array}$ & 15,67 & 17,25 & 16,46 & 5,01 \\
\hline $\begin{array}{l}\text { Bilangan penyabunan }(\mathrm{mg} / \mathrm{g}) \\
\text { Saponification number }(\mathrm{mg} / \mathrm{g})\end{array}$ & 447,32 & 451,10 & 449,21 & \\
\hline $\begin{array}{l}\text { Asam lemak bebas }(\%) \\
\text { Free Fatty Acid }(\%)\end{array}$ & 10,65 & 9,48 & 10,07 & \\
\hline
\end{tabular}

Hasil penelitian menunjukkan bahwa dari bahan biji Tengkawang kering dengan berat $3,50 \mathrm{~kg}$ menghasilkan rendemen lemak Tengkawang rata-rata sebesar 42,86\%. Maharani et al (2016) pembuatan lemak Tengkawang menggunakan "Apit" hanya menghasilkan rendemen $25-30 \%$. Hal ini dimungkinkan karena proses pengepresan menggunakan hidrolik dapat memberikan tekanan yang lebih besar daripada sistem pasak pada "Apit". Santoso et al (2014) membuktikan bahwa untuk memperoleh minyak dari biji karet yang optimum dengan rendemen minyak terbanyak sebesar $31,88 \%$ menggunakan tekanan 120 bar dan memerlukan waktu tekan selama 90 menit. Sedangkan untuk waktu pemanasan tidak memberikan hasil yang signifikan.

Lemak Tengkawang hasil prototipe alat pres Tengkawang memiliki berat jenis $0,90 \mathrm{~g} / \mathrm{cm}^{3}$. Nilai ini hampir sama dengan berat jenis lemak Tengkawang yang dihasilkan dengan metode ekstraksi etanol dengan bantuan enzim (Rahman et al, 2011), yaitu sebesar 0,89. Calvinag et al (2010) berat jenis lemak cokelat berkisar 0,868$0,908 \mathrm{~g} / \mathrm{cm}^{3}$. Hal ini dapat diartikan bahwa berdasarkan kriteria berat jenis, lemak Tengkawang hasil prototipe alat pres Tengkawang dapat digunakan sebagai bahan pengganti atau pencampur lemak cokelat.

Indeks bias lemak Tengkawang hasil pengolahan prototipe alat pres, sebesar 1,45. Nilai ini sama dengan indeks bias lemak Tengkawang yang diteliti oleh Maharani, et al (2016) sebesar 1,45. Sebagai lemak pengganti cokelat, nilai indeks bias lemak Tengkawang sama dengan nilai indeks bias lemak cokelat hasil penelitian Liendo, et al (1997) yang berkisar antara 1,456 hingga 1,457. Nilai indeks bias lemak Tengkawang lebih rendah dibandingkan dengan lemak hewani, seperti yang dilakukan oleh Hermanto et al (2008), 
lemak sapi sebesar 1,460 dan lemak ayam dengan nilai 1,461 .

Titik leleh lemak Tengkawang hasil pengolahan prototipe alat pres sebesar $31^{\circ} \mathrm{C}$. Nilai ini mendekati titik leleh lemak Tengkawang yang diteliti oleh Rahman, et al (2011) yang memiliki titik leleh sebesar $30^{\circ} \mathrm{C}$. Nilai ini lebih rendah dibandingkan dengan margarin dengan bahan baku minyak sawit merah yang memiliki titik leleh $35-36^{\circ} \mathrm{C}$ (Andarwulan et al, 2014). Dassanayake, et al (2011) menyebutkan bahwa semakin tinggi titik leleh lemak/minyak maka semakin besar molekul penyusun yang ada dalam lemak tersebut.

Bilangan iodium lemak Tengkawang hasil "Apit" dari desa Sahan sebesar 20,46 mg/kg (Maharani et al, 2016), nilai ini lebih tinggi dari lemak Tengkawang hasil pengolahan prototipe alat pres sebesar $16,46 \mathrm{mg} / \mathrm{kg}$. Toscano et al (2012) menjelaskan bahwa semakin tinggi nilai iodium lemak, maka lemak tersebut mengandung lemak tak jenuh semakin banyak. Zhang, et al (2012) menyebutkan lemak tak jenuh, memiliki ikatan rangkap yang lebih banyak, berat molekulnya rendah dan lebih sehat bila digunakan dalam bahan makanan.

Bilangan penyabunan lemak Tengkawang dari hasil pengolahan prototipe alat pres sebesar $449,21 \mathrm{mg} / \mathrm{g}$. Nilai ini jauh lebih tinggi dari bilangan penyabunan yang diteliti oleh Rahman, et al (2011) yang hanya sebesar $190,74 \mathrm{mg} / \mathrm{g}$. Bilangan penyabunan lemak Tengkawang lebih tinggi dibandingkan dengan minyak buah merah yang hanya $118,2 \mathrm{mg} \mathrm{KOH} / \mathrm{g}$ (Sarungallo et al,
2013). Tan, et al (2013) menyebutkan bahwa reaksi penyabunan pada lemak atau minyak akan menghasilkan sabun dan gliserin. Artinya lemak Tengkawang hasil prototipe alat pres dapat digunakan sebagai bahan baku sabun.

Fernie et al (2004) nilai Free Fatty Acid (FFA) dalam makanan mempengaruhi kadar kolesterol dalam darah. Hasil pengujian menunjukkan bahwa kadar FFA lemak Tengkawang dari hasil pengolahan prototipe alat pres sebesar 10,07\%. Nilai ini lebih tinggi dari (Maharani et al, 2016) nilai kadar FFA lemak Tengkawang dari desa Sahan yang hanya 5,01\%. Nilai FFA ini lebih tinggi daripada nilai FFA ekstraksi lemak Tengkawang yang dilakukan secara lab yang dilakukan oleh Gusti dan Zulnely (2015) yang menghasilkan nilai FFA 3,22 untuk Shorea mecistopteryx. Li, et al (2011) menyebutkan bahwa kadar FFA yang tinggi dalam lemak akan mengurangi kualitas bau dan kestabilan minyak/lemak. FFA lemak Tengkawang hasil pengolahan prototipe alat pres yang tinggi diakibatkan karena biji Tengkawang yang digunakan untuk pengepresan berasal dari hasil panen JanuariFebruari 2015 dan telah disimpan hingga November 2015 karena menunggu proses pembuatan prototipe alat pres.

\section{KESIMPULAN}

Pengenalan prototipe alat pres hidrolik untuk pengepresan biji Tengkawang, mampu mengatasi kondisi beban kerja berat dari alat pres tradisional "Apit", alat dimaksud bahkan 
mampu bekerja dengan kapasitas tekan hingga 1 ton.

Lemak Tengkawang hasil dari proses pres hidrolik memberikan rendemen optimum mencapai 42,68\%, jika dibandingkan lemak Tengkawang hasil alat pres "Apit" dengan rendemen optimum berkisar $25-30 \%$.

Sementara itu, karakteristik lemak Tengkawang yang dihasilkan dari prototipe alat pres hidrolik mengindikasikan hasil lemak Tengkawang dengan kualitas, bau dan kestabilan lemak yang lebih baik dan dapat langsung digunakan sebagai bahan dasar produk turunan lemak Tengkawang lainnya.

\section{UCAPAN TERIMA KASIH}

Tulisan ini didedikasikan untuk mengenang Almarhumah Dr. Widayati yang telah banyak memberikan saran dan masukan saat mendesain prototipe alat pres Tengkawang. Ucapan terima kasih juga penulis ucapkan kepada Ahmad Rifai yang banyak membantu dalam proses pembuatan prototipe alat pres Tengkawang.

\section{DAFTAR PUSTAKA}

Andarwulan, N., D. R. Adawiyah, N. Wulandari, P. Hariyadi, R. N. Triana, A. R. Affandi, R. C. Nur, S. Tjahjadi dan M. F. Ellen. 2014. Aplikasi margarin minyak sawit merah pada produk pound cake dan roti manis. Prosiding Seminar hasil-hasil PPM IPB 2014. Vol. 1. Hal. 192-206.

Calvinag, B., E. Rodier, J.J. Letourneau, P. M. A. Santos dan J. Fages. 2010. Cocoa Butter Saturated with Supercritical Carbon Dioxide:
Measurement and Modelling of Solubility, Volumetric expansion, Density and Viscosity. International Journal of Chemical Reactor Engineering. Vol. 8. Hal. 1-29.

Dassanayake, L. S. K., D. R. Kodali dan S. Ueno. 2011. Formation of Oleogels Based on Edible Lipid Materials. Current Opinion in Coloid and Interface Science Journal. Vol. 16. Hal. 432-439. Elsevier.

Dewangan, A.K., A. D. Patel dan A. G. Badhania. 2015. Stainless Stell for Diary and Food Industry: A Review. Material Science and Engineering Journal. Vol. 4. No. 5. Hal. 1-4.

Fernie, C.E., I. E. Dupont, O. Scruel, Y. A. Carpentier, J. L. Sebedio dan C. M. Scrimgeour. 2004. Relative absorption of conjugated linoleic acid as triacylglycerol, free fatty acid and ethyl ester ini a functional food matrix. European Journal Lipid Science Technology. Vol. 106. Hal. 347-354.

Gunstone, F. D. 2011. Vegetable Oils in Food Technology: Composition, Properties and Uses. $2^{\text {nd }}$ Edition. Willy-Blackell Company.

Gusti, R. E. P. dan Zulnely. 2015. Pemurnian Beberapa Jenis Lemak Tengkawang dan Sifat Fisiko Kimia. Jurnal Penelitian Hasil Hutan. Vol. 33. No. 1. Hal. 61-68.

Hermanto, S., A. Muawanah dan R. harahap. 2008. Profil dan Karakteristik Lemak Hewai (Ayam, sapid an babi) hasil analisa FTIR dan GCMS. Laporan Penelitian. Universitas Hidayatullah Jakarta.

Jahurul, M.H.A., ISM Zaidul, NAN Norulaini, F Sahena, S Jinap, J Azmir, KM Sharif dan AKM Omar. 2013. Cocoa butter fats and possibilities of substitution in food products concerning cocoa varieties, alternative source, extraction methods, composition and characteristics. Journal of Food engineering. Vol. 117. Hal. 467-476. Elsevier.

Li, G., J. You, Y. Suo, C. Song, Z. Sun, L. Xia, X. Zhao dan J. Shi. 2011. A Developed Precolumm Derivatization Method for the Determination of Free Fatty Acids in Edible Oils by Reversed-phase HPLC with 
Fluorescence Detection and Application to Lycium barbarum Seed Oil. Food Chemistry Journal. Vol. 125. Hal. 1365-1372. Elsevier.

Liendo, R., F. C. Padilla dan A. Quintana. 1997. Characterization of Cocoa Butter Extracted from Criollo Cultivars of Theobroma cacao L. Food Research International Journal. Vol. 30. No. 9. Hal. 727-731. Elsevier.

Maharani, R, A. Fernandes dan R. Pujiarti. 2016. Comparison of Tengkawang Fat processing and its effect on Tengkawang fat quality from sahan and nanga yen villages, west Kalimantan, Indonesia. AIP Conference Proceeding: Towards the sustainable use of biodiversity in a changing environment from basic to applied research. Hal. 020051-1 020051-5.

Ohijeagbon, I. O., M. A. Waheed, dan S. O. 2013. Methodology for the Physical and Chemical Exergetic Analysis of Steam Boilers. Energy Journal. Vol. 53. Hal. 153-164. Elsevier.

Quan, Z., L. Quan dan J. Zhang. 2014. Review of Energy Efficient Direct Pump Controlled Cylinder ElectroHydraulic Technology. Renewable and Sustainable Energy Reviews Journal. Vol. 35. Hal. 336-346. Elsevier.

Rahman, N. F. A, M. Basri, M. B. A. Rahman, R. N. Z. R. A. Rahman dan A. B. Salleh. 2011. High Yield Lipase-catalyzed Systhesis of Engkabang Fat Esters fo the Cosmetic Industry. Bioresource Technology. Vol. 102. Hal. 2168-2176. Elsevier.
Santoso, H., Iryanto dan M. Inggrid. 2014. Effect of Temperature, Preasure, Preheating Time and Pressing Time on Rubber Seed Oil Extraction Using Hydraulic Press. Procedia Chemistry Journal. Vol. 9. Hal 248-256. Elsevier.

Sarulanggo, Z. L., Murtiningrum, B. Santoso dan M. K. Roreng. 2013. Pengaruh penanganan pasca panen terhadap kualitas minyak buah merah (Pandanus conoideus). Prosiding seminar PATPI 2013.

Sumarhani. 2007. Pemenfaatan dan Konservasi Jenis Meranti Merah Penghasil Tengkawang. Info Hutan. Vol. IV. No. 2. Hal. 177-185.

Tan, H. W., A. R. A. Aziz, dan M. K. Aroua. 2013. Glyserol Production and Its Applications as a Raw Material: A Review. Renewable and Sustainable Energy Reviews Journal. Vol. 27. Hal. 118-127. Elsevier.

Toscano, G., G. Riva, E. F. Pedretti dan D. Duca. 2012. Vegetable Oil and Fat Viscosity Forecast Models Based on Iodine Number and Saponification Number. Biomass and Bioenergy Journal. Vol. 46. Hal. 511-516. Elsevier.

Zhang, Q., A. S. M. Saleh, J. Chen dan Q. Shen. 2012. Chemical Alterations Taken Place During Deep-fat Frying Based on Certain Reaction Products: A Review. Chemistry and Physics of Lipids Journal. Vol. 165. Hal. 662681. Elsevier. 
JURNAL Penelitian Ekosistem Dipterokarpa Vol.3 No.2, Desember 2017: 49-56 